\title{
変形性膝関節症および関節リウマチ患者に対する 人工膝関節全置換術後の膝屈曲可動域の改善角度の違い
}

\author{
眞田祐太朗 ${ }^{1,3 \dagger}$, 大澤 傑 ${ }^{1,2}$, 椎木孝幸 ${ }^{1}$, 今高康詞 ${ }^{1}$, \\ ${ }^{1}$ 行岡病院リハビリテーション科, ${ }^{2}$ 大阪行岡医療大学医療学部理学療法学科, \\ ${ }^{3}$ 現所属: 神戸海星病院リハビリテーションセンター
}

\begin{abstract}
要旨:術前の関節可動域（ROM）に有意差を認めない条件下で, 人工膝関節全置換術（TKA）後 1 年時点の変形性膝関節症（膝 OA）と関節リウマチ（RA）患者における膝屈曲 ROM の改善角度の違いを明らかにすることを目的とした．対象は膝 OA 患 者 22 名 28 膝, RA 患者 15 名 17 膝とした。術前 ROM に基づいて $130 \mathrm{deg}$ 以上の良好群と $130 \mathrm{deg}$ 未満の中間群に分類し, その上で膝 $\mathrm{OA}$ 群と RA 群の 2 群に分類した。 術前に対する術後 1 年の改善角度を算出し, 両疾患間で比較を行った. ROM の改善角度は, 良好群では両疾患間に有意な差を認めなかったものの, 中間群では膝 OA 群に比べRA 群の方が有意に大き かった. TKA 後 1 年の改善角度は, 術前 ROM が 130 deg 以上の場合には疾患による違いはないが, $130 \operatorname{deg}$ 未満の場合には 膝OA に比べRAの方が大きくなることが示唆された.
\end{abstract}

キーワード：人工膝関節全置換術，関節可動域，予後予測，変形性膝関節症，関節リウマチ

\section{1.はじめに}

関節可動域（Range of Motion；以下, ROM）は, 人工滕 関節全置換術（Total Knee Arthroplasty；以下, TKA）後の 術後成績を左右する重要な指標の一つである ${ }^{1)}$. TKA 後の滕 屈曲 ROM を検討した先行研究では, 術前 ROM と正の相関 にあること ${ }^{2-4)}$, 術前 ROM が影響すること ${ }^{5,6)}$, 術前不良群 は術後 ROM が低值であること ${ }^{7,8)}$, 術後不良群は術前 ROM が低值であること ${ }^{9}$ などが報告されている。このように, 術 前 ROM が術後 ROM の重要な決定因子であることが明らか となっている. したがって, 術後にROM の改善を図るうえ では，術前 ROMに基づいた予後予測を行い，個別性に配慮 した理学療法介入を行っていくことがきわめて重要である.

TKA は末期の変形性膝関節症（Knee Osteoarthritis；以下， 膝 OA）患者だけでなく, 関節破壊の進行した関節リウマチ （Rheumatoid arthritis；以下, RA）患者の関節再建術として も広く普及している。しかしながら, 術後の ROM 練習は画 一的に実施されることが多く, 疾患の違いが反映されている とは言い難いのが現状である. さらに, 理学療法の実施頻度 について，入院中は週 5 日から休みなく実施されているもの の, 退院後は急激に減少することがほとんどである. 毎年増

2017 年 2 月 23 日受付 2018 年 3 月 9 日受理

${ }^{\dagger}$ \% 657-0068 兵庫県神戸市灘区篠原北町 3-11-15

神戸海星病院リハビリテーションセンター

眞田祐太朗

Tel: 078-871-5201 Fax: 078-871-5206

E-mail: sanada.yutaro@gmail.com
加の一途をたどっている医療費を抑制するため，入院期間の 短縮が求められているが, 退院後に扔ける理学療法の必要性 や実施頻度について明確な根拠は示されていない。したがっ て, 両疾患に扔ける術後 ROM の推移を明らかにし, 疾患の 違いに応じた介入方法を提案することで, 理学療法を適切に 提供していく必要がある.

膝 OA と RA 患者における術後 ROM の推移については, いくつかの縦断研究が行われている. 膝伸展 ROM が制限さ れた状態である屈曲拘縮は, 両疾患とも術後に改善すること が報告されており ${ }^{2,3,5,10,11)}$, 滕 OA に比べRA の方が有意に 改善したとする報告も見受けられる $2,10,11)$.このように, 膝 伸展 ROM は両疾患で等しく, あるいは RA に有意な改善が 得られることが示されている.

対して, 膝屈曲 ROMについては報告によって異なる結果 が示されている.術後 6 週の膝屈曲 ROMについて戸田ら”は, 滕 OA に比べRA の方が有意に大きかったと報告している. また Harvey $ら^{5)}$ は術後 1 年, 小林ら ${ }^{2)}$ は術後 $1 \sim 2$ 年半に おける膝屈曲 ROM の術前に対する術後改善度について, い ずれも膝 OA では低下したが RA では増加したと報告してい る. 一方で術後 2 年の膝屈曲 ROM について Schurman ら ${ }^{10)}$ は, RA に比べ膝 OA の方が有意に大きかったと報告してい る. また術後 $2 \sim 4$ 年の膝屈曲 ROM について Ryu ら ${ }^{9)}$ は, RA に比べ膝 OA の方が $120 \mathrm{deg}$ 以上の良好例の割合が高か ったと報告している. さらに興座ら ${ }^{3)}$ は術後 $10 \sim 14$ 年の長 期成績を調查し, 術前後に扔ける膝屈曲 ROM を比較検討し た. その結果, 膝 $\mathrm{OA} て ゙ は$ 有意な差を認めなかったが RA で は術後に有意な低下を認めたと報告し，その要因として多関 
節障害と骨粗鬆症を挙げている. このように, 膝屈曲 ROM は疾患の違いによって術後の推移も異なることが示されてお り，長期的には滕 OA に比べ多関節に障害を有することが多 いRAの方が低下することが示唆されている.しかしながら， 術後 1 年以内の短期成績について統一した見解は得られてい ない. 臨床では, 膝 OA に比べRA の方が ROM の改善が容 易であることを経験するが, 疾患別の介入方法を提案してい くためには, 数多くの臨床研究の蓄積が必要である. 加えて, 術後 ROM の改善度は術前 ROM に依存することが報告され ているが7)，これまでに術前 ROM に有意差を認めない条件 下で比較検討した報告はほとんどない.

そこで本研究では, 術前 ROM に有意差を認めない条件 下で, TKA 後 1 年時点の膝 OA と RA 患者における膝屈曲 ROM の改善角度の違いを明らかにすることを目的とした。

\section{2. 対象および方法}

\section{1 対象}

対象は滕 OA ならびに RA を原疾患とし, 2012 年 10 月 から 2014 年 10 月に当院にて TKA を施行した 37 名 45 膝 とした。内訳は膝 OA が 22 名 28 膝（女性 28 膝, 年齢 72.5 \pm 5.8 歳), RA が 15 名 17 膝 (女性 13 膝, 男性 4 膝, 年齢 $70.8 \pm 7.1$ 歳) であった. 膝 OA 患者における罹患関節の内 訳は, 両側が 18 名, 片側が 2 名, 対側施行後が 2 名であっ た. また, Kellgren-Lawrence 分類 ${ }^{12)}$ による術側の重症度は, 全例 grade IV であった. RA 患者における Larsen の grade 分 類 ${ }^{13)}$ による術側の関節破壊の程度は, 全例 grade IVであっ た. 使用機種はすべて日本ストライカー社製で, 膝 OAには Triathlon ${ }^{\circledR}$ CS が使用され, 後十字勒帯 (Posterior Cruciate Ligament; 以下, PCL) は9膝で温存, 19 膝で切離された. RA には Triathlon® PS が 8 膝, Scorpio® NRG PS が 9 膝に 使用され, PCL はいずれも切離された.

取り込み基準は 60 歳以上, 同一の術者による TKA, 術前 の Timed Up and Go test (以下, TUG) の值が 30 秒未満の 者とした。除外基準は術前に膝が強直していた者, 術後に脳 梗塞を発症した者, 膝関節を除く下肢関節に手術が適応とな る重度の機能障害を有する者, アメリカリウマチ学会による 機能障害度 ${ }^{14)}$ が class IVであった者とした. 取り込み基準を 満たし，除外基準に該当しなかった者は，下肢関節を除く多 関節に障害を有していても対象に取り込んだ。手術は minimidvastus approachで関節に達し, Modified Gap Technique で施行された，膝蓋骨は全例で置換され， lateral release は施 行されなかった，各コンポーネントは骨セメントを用いて固 定された。なお, 使用した機種の許容度と実際の術中所見, 当院における過去の術後成績も考慮し, 膝 ROM の術後目標 值は屈曲 $130 \sim 135 \mathrm{deg}$, 伸展 $0 \mathrm{deg}$ に設定された.

\section{2 介入内容}

術後理学療法は, 当院のクリニカルパス (Clinical pathways ; 以下, CP) に準じて, 術後翌日から段階的に介 入し, 術後 3 週から 5 週での退院を目標に実施した. CP の

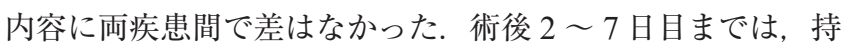
続的他動運動 (Continuous Passive Motion;CPM) を使用した. 担当は 10 名の理学療法士から無作為に選出された. 術後の 平均入院期間は膝 $\mathrm{OA}$ が $35.4 \pm 10.6(17$ 65) 日, RA が $44.4 \pm 16.3(25 \sim 83)$ 日であった. 退院後は疾患に関わらず, 主治医の外来診察と並行して原則月 1 回の頻度で実施した.

\section{3 評価項目および方法}

対象者は手術前日に入院し, その日にベースライン調査 を行った. 調査項目は性別, 年齢, 身長, 体重, Body Mass Index (BMI), 疾患名, 罹患期間, 大腿脛骨角 (Femorotibial Angle; FTA), 膝屈曲 ROM とした. さらに, 追跡調査と して術後 1 週, 2 週, 3 週, 4 週および 3 力月, 6 力月, 12 カ月における膝屈曲 ROM を測定した. そして, 術後 12 力 月と術前の測定值の差から, 術後の改善角度を算出した. ROM は, 日本整形外科学会および日本リハビリテーション 医学会が規定する測定方法に準じて，対象者を背臥位とし， ゴニオメーターを用いて他動的に $5 \mathrm{deg}$ 単位で測定し, 治療 前の值を採用した。罹患期間は, 膝 OA では診断日と問診か ら滕に疼痛や変形を感じ始めた時期を調查し, いずれか早い 日から手術日までの期間, RA では診断日から手術日までの 期間を年単位で算出した.

\section{4 統計学的解析}

膝屈曲 ROM の術後目標值が 130 ～ 135 deg であったこと から, 術前 ROM がそれを上回る者と下回る者とに分けて検 討するため, 対象者数の均衡にも配慮し, 術前 ROM に基づ いて $130 \mathrm{deg}$ 以上の良好群と $130 \mathrm{deg}$ 未満の中間群に分類し, その上で膝 $\mathrm{OA}$ 群と RA 群の 2 群に分類した（表 1,2 ）。 そ

表 1 対象者のベースライン属性

\begin{tabular}{lcccc} 
& \multicolumn{2}{c}{ 良好群 } & \multicolumn{2}{c}{ 中間群 } \\
\cline { 2 - 5 } & Knee OA & RA & Knee OA & RA \\
\hline 対象 (名/滕) & $13 / 15$ & $6 / 7$ & $9 / 13$ & $9 / 10$
\end{tabular}

性別 (男性/女性) $\quad 0 / 15 \quad 1 / 6 \quad 0 / 13 \quad 2 / 8$

年齢(歳) $\quad 73.5 \pm 4.5 \quad 74.6 \pm 4.5 \quad 71.3 \pm 6.8 \quad 68.1 \pm 7.3$ $\mathrm{BMI}\left(\mathrm{kg} / \mathrm{m}^{2}\right) \quad 25.4 \pm 3.0 \quad 22.4 \pm 2.0 \quad 26.0 \pm 2.7 \quad 25.9 \pm 5.2$ FTA $\left(^{\circ}\right) \quad 183.8 \pm 3.8181 .4 \pm 6.0185 .7 \pm 5.2177 .7 \pm 6.0$ 罹患期間 $($ 年 $) \quad 10.3 \pm 6.2 \quad 15.1 \pm 10.3 \quad 11.8 \pm 5.0 \quad 17.9 \pm 15.9$ 平均 \pm 標準偏差. Knee OA: 変形性膝関節症, RA：関節リウマチ, BMI：体格指数, FTA : 大腿脛骨角.

表 2 対象者の使用機種

\begin{tabular}{lccccc} 
& & \multicolumn{2}{c}{ 良好群 } & \multicolumn{2}{c}{ 中間群 } \\
\cline { 3 - 6 } & & Knee OA & RA & Knee OA & RA \\
\hline Triathlon CS & (PCL 温存 $)$ & 5 & - & 4 & - \\
Triathlon CS & (PCL 切離 $)$ & 10 & - & 9 & - \\
Triathlon PS & (PCL 切離 $)$ & - & 3 & - & 5 \\
Scorpio PS & (PCL 切離 $)$ & - & 4 & - & 5 \\
\hline
\end{tabular}

PCL : 後十字勒帯. 
して, 良好群と中間群のそれぞれで, 膝 OA 群とRA 群の両 疾患間に打ける術前 ROM と術後 12 力月の改善角度を比較 した，統計解析は，まず Shapiro-Wilk 検定を用いて各群が 正規分布にしたがうか否かを確認したところ，すべての比較 対象に正規性が裹却された群が含まれていた，そのため， 2 群間の比較には Mann-WhitneyのU 検定を用いた．統計ソ フトはEZR version $1.33^{15)}$ を用いて, 有意水準は $5 \%$ 未満と した。

\section{5 倫理的配慮}

本研究は,「ヘルシンキ宣言」ならびに厚生労働省の「臨 床研究に関する倫理指針」に基づいて計画された．対象者に は本研究の趣旨と内容, デー夕の利用に関する説明を行い, 参加の同意を得た。倫理的配慮として, 行岡病院倫理委員会 の承認を得た（承認番号：H2605-003）。

\section{3. 結果}

各群に㧍ける滕屈曲 ROM の推移を図 1 に示す. 両疾患群 ともに，中間群に比べ良好群の方が大きい傾向にあった，ま た, 中間群の膝 $\mathrm{OA}$ の久術後 3 力月以降は減少傾向にあった. つぎに，ベースラインに扩ける術前の膝屈曲 ROM は，良好 群と中間群のそれぞれで両疾患間に有意差を認めなかった (表 3)。そして, 術前に対する術後 1 年の膝屈曲 ROM の改 善角度 [中央值 (四分位範囲) ］は，良好群では膝 OA［$5.0(-10.0 \sim 0.0)]$ と RA $[0.0(-5.0 \sim 0.0)]$ に有意な 差を認めなかったものの, 中間群では滕 OA $[0.0$ （－5.0〜 5.0)］に比べ RA [5.0（5.0～10.0）の方が有意に高值を示 した $(\mathrm{p}<0.01)$ (表 4$)$.

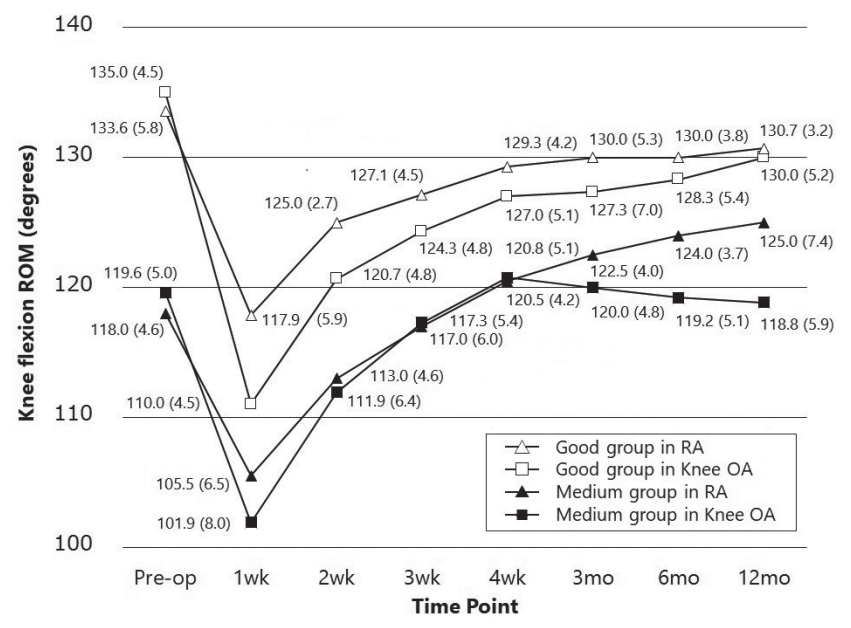

図 1 膝屈曲 $\mathrm{ROM}$ の平均值（標準偏差）の推移

表 3 術前の膝屈曲 ROM の比較

\begin{tabular}{ccc} 
& Knee OA & RA \\
\hline 良好群 & $135.0(132.5-135.0)$ & $130.0(130.0-135.0)$ \\
中間群 & $120.0(115.0-125.0)$ & $120.0(116.3-120.0)$ \\
\hline
\end{tabular}

中央値 (四分位範囲)。単位 : 。
表 4 術後 1 年における膝屈曲 ROM の改善角度の比較

\begin{tabular}{lll} 
& Knee OA & RA \\
\hline 良好群 & $-5.0(-10.0 \sim 0.0)$ & $0.0(-5.0 \sim 0.0)$ \\
中間群 & $0.0(-5.0 \sim 5.0)$ & $5.0(5.0 \sim 10.0) * *$ \\
\hline 中央值 $\left(\right.$ 四分位範囲). 単位 : ${ }^{\circ} . * *: \mathrm{p}<0.01$. \\
術後 1 年の值から術前の值を引いた值を改善角度として算出. 良 \\
好群では両疾患間に有意な差を認めないが, 中闍では変形性膝 \\
関節症に比べ関節リウマチの方が有意に大きい.
\end{tabular}

\section{4. 考察}

本研究の結果, 中間群では滕 $\mathrm{OA}$ に比べ RA の方が有意 に改善角度は大きかった. ROM の制限因子は, 不動後 2 週 までは骨格筋， 2 週以降は関節構成体が優位になることが報 告されている ${ }^{16)}$. 沖田ら ${ }^{177}$ は, 不動が骨格筋に及ぼす影響 について検討した結果, 筋線維では筋原線維の退行性変化や 筋節長の短縮, 筋膜では筋周膜や筋内膜の肥厚やコラーゲン 線維に配列変化を認めたと報告している。，一方，関節構成体 である関節包では, 滑膜細胞の增殖ではなく, 滑膜内膜の癒 着が ROM 制限に関与することが示唆されている ${ }^{18)}$. したが って, TKA 術前の膝 OA および RA 患者の膝屈曲 ROM 制 限には, 滕蓋骨, 大腿骨, 脛骨関節面に㧍ける軟骨変性や骨 棘形成に, 大腿四頭筋や膝蓋腱の短縮だけでなく, 膝蓋上 囊の瘉着に伴う膝蓋骨の遠位への滑走制限, 前方関節包の 癒着などの因子が複合的に関与していると考えられる。ただ し, 膝関節破壊に至る要因は, 膝 $\mathrm{OA}$ では膝関節構成体の退 行変性を基盤とするのに対して ${ }^{19)}$, RA は関節滑膜を主病変 とする炎症とそれに伴う炎症性サイトカインの産生や滑膜増 殖によって, 骨抢よび軟骨組織や軟部組織の破壊がもたらさ れる ${ }^{20)}$. すなわち, 関節破壊の要因が退行変性に起因する膝 OA と炎症に起因する RA では, TKA 後も温存される軟部 組織の状態が異なることが推察される，以上のことから，膝 $\mathrm{OA}$ では滕蓋上囊や前方関節包の癒着, 大腿四頭筋や膝蓋腱 の短縮の改善が得られなかったことで術後も術前と同程度の ROM となり, RA ではこれらの制限因子の関与が少なかっ たことで術後に改善を認めたのではないかと考える.

良好群では, 両疾患ともに術後 ROM は術前 ROM を下回 っていたものの, 中間群よりは大きい傾向にあり, 両疾患間 では有意差を認めなかった。本研究の対象に用いた使用機 種は, いずれも構造的には $150 \mathrm{deg}$ の膝屈曲 ROM が許容さ れている. しかしながら，当院における目標值は $130 \sim 135$ deg であったことから, 術前 ROM がこれを上回っていた対 象者に打いては, 術後 ROM は必然的に低下したと考元られ る. 以上のことから, 術前 ROM が $130 \mathrm{deg}$ 以上の場合には, 術後の目標値に応じて減少する可能性はあるものの, 疾患に 限らず術後も良好な膝屈曲 ROM が獲得できることが示唆さ れた。

また，本研究の対象に使用された機種について，膝 OA は cruciate substituting（以下，CS）型であったのに対して, 
RA は Posterior Stabilized（以下, PS）型であった. CS 型は インサートの隆起した前方リップによって, 前後方向の適合 性と脛骨の後方安定性を高めたデザインである，なお， PCL は温存および切離の両術式で使用可能であるが, 本研究では 9 膝で温存, 19 膝で切離がなされた. 一方, PS 型は PCL を 切離し, 脛骨インサートと大腿骨コンポーネントの post-cam 機構によって関節運動を機械的に安定させるデザインであ る. 使用機種別の術後 ROM については, メタアナリシス研 究 ${ }^{21,22)}$ において, PCL を温存する cruciate retaining（以下, CR) 型に比べて, PS 型の方が優れていることが示されている.

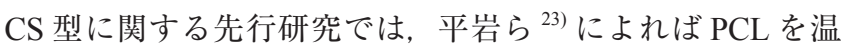
存した CS 型は, 術前に対して術後 ROM は減少したものの, それ以前に用いていた CR 型とは大差なかったと報告してい る. 一方, PCL を切離した CS 型では, PS 型と有意な差はな かったとする報告が散見されている ${ }^{24,25)}$ ，そして，関谷ら ${ }^{26)}$ は CS 型 TKA における PCL 温存と切離の違いが術後 ROM に与える影響について検討した結果, 術前 ROM が $110 \mathrm{deg}$ 以上 $130 \mathrm{deg}$ 未満であった群では, PCL 温存と切離の両術 式間に有意な差は認めなかったものの, $130 \mathrm{deg}$ 以上の群で は PCL 切離の方が有意に大きかったと報告している.これ らをまとめると, 使用機種別の術後 ROM は, PS 型が最も 優れており, それに比べると CR 型は劣っている可能性が高 い. そして, CS 型においては, PCLを切離した場合にはPS 型と同等の成績が得られるものの, PCL を温存した場合に はやや劣り，その影響は術前 ROM が良好であるほど大きく なることが推測される，本研究では，膝 OA 患者には CS 型 TKA が施行されたが，このうち PCL を温存とした割合は良 好群で約 33\%, 中間群で約 31\%であり, いずれも半数に満 たなかった. したがって, 膝 OA 群で PCLを温存とした CS 型 TKA が含まれていたことによる術後 ROMへの影響は少 ないと考える.

本研究結果から, 術前 ROM が $130 \mathrm{deg}$ 未満の場合, RA では術前を上回る良好な術後 ROM が期待できること, 膝 $\mathrm{OA}$ では術後 4 週まで段階的に改善するものの, 3 力月以降 は低下して，1 年時点では術前と同程度の ROM になるこ とが示唆された. 疾患別の理学療法介入を考えるうえでは, RA では TKAによって膝関節が再建されても疾患が治癒し たわけではないため, 術後も投薬を中心に症状をコントロー ルしていく必要がある. そのため, 術後 4 週時点で術前值あ るいは術後目標值が獲得されていれば, 退院後は頻繁に介入 するよりも, より長期的な視点でフォローアップしていくこ とが重要と考えられる. そして膝 OA では, 術前 ROM が術 後目標值を下回っている場合, 術後可及的早期より膝蓋上囊 や前方関節包の癒着. 大腿四頭筋や膝蓋腱の短縮の改善を積 極的に図りながら, 術後 4 週以降も状態に応じて定期的にフ オローアップしていく必要があると考える.

本研究の限界として, まず膝 OA 患者では両側罹患例にお ける非術側 ROM の影響を考慮できていない点, RA 患者で は疾患活動性を評価できていない点が挙げられる. 次に, 術
前の身体機能として ROM が $110 \mathrm{deg}$ 未満かつ TUG が 30 秒 以上の者を除外基準としたため, 術前に重度の ROM 制限や 移動機能の低下を有する患者にまで一般化できない点が挙げ られる。それから，両疾患群間で男女の割合が統一されてい ないため, 性差がどの程度影響を与えているかは不明である. また使用機種については，本研究では膝 OA 患者には CS 型, RA 患者はPS 型を使用したことから，これと異なる条件下 で両疾患間の比較をする際には注意が必要である.さらに, 調查期間が術後 1 年と短期間であったことから, 中長期的な 予後については言及できない。 そして, 術後因子を両疾患間 で完全には統一できておらず，それらが術後改善角度に影響 した可能性は否定できない. 今後の課題として, より多くの 症例を対象とした長期的な追跡調査において, 術前 ROM だ けでなく術後因子の影響も加味した上で再度検討する必要が ある。

\section{5. 結語}

術前 ROM に有意差を認めない条件下で, TKA 後 1 年時 点の膝 $\mathrm{OA}$ と RA 患者における膝屈曲 ROM の改善角度を 比較した. 結果より, 改善角度は術前 ROM が $130 \mathrm{deg}$ 以 上の場合には疾患による違いはないが, $130 \mathrm{deg}$ 未満の場合 には膝 OA に比べRAの方が大きくなることが示唆された. 本研究で得られた知見は, TKA 後の膝屈曲 ROM を疾患別 に予測し, 疾患の違いに応じて理学療法を適切に提供して いくための一助となると考えられる.

\section{参考文献}

1) Ritter, M. A., Lutgring, J. D., Davis, K. E. and Berend, M. E.: The effect of postoperative range of motion on functional activities after posterior cruciate-retaining total knee arthroplasty, The Journal of Bone and Joint Surgery. American Volume, 90(4), 777-784, (2008).

2) 小林千益, 武井経憲, 八木了, 間宮典久: 慢性関節リ ウマチと変形性滕関節症に対する I/BII 型 (PS 型) 人工 膝関節置換術の臨床評価, 日関外誌, 7(1), 79-87, (1988).

3) 與座格, 金谷文則, 濱崎直人, 吉川朝昭, 古堅隆司, 大湾一郎, 大嶺啓, 茨木邦夫, 知念弘：当科における 人工膝関節置換術の長期成績, 整形外科と災害外科, 49(1), 42-46, (2000).

4) Bade, M. J., Kittelson, J. M., Kohrt, W. M. and StevensLapsley, J. E.: Predicting functional performance and range of motion outcomes after total knee arthroplasty, American Journal of Physical Medicine \& Rehabilitation, 93(7), 579-585, (2014).

5) Harvey, I. A., Barry, K., Kirby, S. P., Johnson, R. and Elloy, M. A.: Factors affecting the range of movement of total knee arthroplasty, The Journal of Bone and Joint Surgery. 
British Volume, 75(6), 950-955, (1993).

6) Gatha, N. M., Clarke, H. D., Fuchs, R., Scuderi, G. R. and Insall, J. N.: Factors affecting postoperative range of motion after total knee arthroplasty, Journal of Knee Surgery, 17(4), 196-202, (2004).

7) 戸田秀彦, 戸田香, 木山喬博, 三宅洋之：人工膝関 節置換術後の屈曲可動域予測, 理学療法科学, 26(3), 411-415, (2011).

8) Bin Abd Razak, H. R., Han, X. A., Chong, H. C. and Tan, H. C.: Total knee arthroplasty in Asian subjects: preoperative range of motion determines postoperative range of motion?, Orthopaedic Surgery, 6(1), 33-37, (2014).

9) Ryu, J., Saito, S., Yamamoto, K. and Sano, S.: Factors influencing the postoperative range of motion in total knee arthroplasty, Bulletin of Hospital for Joint Disease, 53(3), 35-40, (1993).

10) Schurman, D. J., Parker, J. N. and Ornstein, D.: Total condylar knee replacement. A study of factors influencing range of motion as late as two years after arthroplasty, The Journal of Bone and Joint Surgery. American Volume, 67(7), 1006-1014, (1985).

11) Tew, M. and Forster, I. W.: Effect of knee replacement on flexion deformity, The Journal of Bone and Joint Surgery. British Volume, 69(3), 395-399, (1987).

12) Kellgren, J. H. and Lawrence, J. S.: Radiological assessment of osteo-arthrosis, Annals of the Rheumatic Diseases, 16(4), 494-502, (1957).

13) Larsen, A., Dale, K. and Eek, M.: Radiographic evaluation of rheumatoid arthritis and related conditions by standard reference films, Acta Radiologica: Diagnosis, 18(4), 481491, (1977).

14) Hochberg, M. C., Chang, R.W., Dwosh, I., Lindsey, S., Pincus, T. and Wolfe, F.: The American college of rheumatology 1991 revised criteria for the classification of global functional status in rheumatoid arthritis, Arthritis \& Rheumatism, 35(5), 498-502, (1992).

15) Kanda, Y.: Investigation of the freely available easy-touse software 'EZR' for medical statistics, Bone Marrow Transplant, 48(3), 452-458, (2013).

16) Trudel, G. and Uhthoff, H. K.: Contractures secondary to immobility: is the restriction articular or muscular? An experimental longitudinal study in the rat knee, Archives of Physical Medicine and Rehabilitation, 81(1), 6-13, (2000).

17) 沖田実, 吉村俊朗, 田原弘幸, 加藤克知, 中野裕之, 井口茂, 中野治郎：関節固定がラットヒラメ筋の筋内 膜コラーゲン線維網の構築におよぼす影響, 理学療法 学, 24(1), 23-30, (1997).

18) Trudel, G., Jabi, M. and Uhthoff, H. K.: Localized and adaptive synoviocyte proliferation characteristics in rat knee joint contractures secondary to immobility, Archives of Physical Medicine and Rehabilitation, 84(9), 13501356, (2003).

19) 古賀良生 : 変形性膝関節症 - 病態と保存療法, 2-4, 南 江堂, (2008).

20) 西田圭一郎：関節リウマチの病態と整形外科的治療, 理学療法, 25(1), 305-310, (2008).

21) Bercik, M. J., Joshi, A. and Parvizi, J.: Posterior cruciateretaining versus posterior-stabilized total knee arthroplasty: a meta-analysis, The Journal of Arthroplasty, 28(3), 439444, (2013).

22) Jiang, C., Liu, Z., Wang, Y., Bian, Y., Feng, B. and Weng, $\mathrm{X}$.: Posterior cruciate ligament retention versus posterior stabilization for total knee arthroplasty: A Meta-Analysis, PLoS One, 11(1), e0147865, (2016).

23) 平岩秀樹, 酒井忠博, 演田恭, 小田智之, 高松晃, 山 下暁士, 宮本健太郎, 土谷早穂, 岸本烈純, 石黑直樹 : PCL を温存した CS 型 TKA における術後可動域の検討, 日本人工関節学会誌, 45, 451-452, (2015).

24) Scott, D. F. and Smith, R. R.: A prospective, randomized comparison of posterior stabilized versus cruciatesubstituting total knee arthroplasty: a preliminary report with minimum 2-year results, The Journal of Arthroplasty, 29(9 Suppl), 179-181, (2014).

25) Sur, Y. J., Koh, I. J., Park, S. W., Kim, H. J. and In, Y.: Condylar-stabilizing tibial inserts do not restore anteroposterior stability after total knee arthroplasty, The Journal of Arthroplasty, 30(4), 587-591, (2015).

26) 関谷仁, 金谷裕司, 高徳賢三, 木村明徳, 高田尚 : 同 一人工膝関節機種における後十字䩲帯温存・切除によ る術後可動域の比較, 日本人工関節学会誌, 45, 449450, (2015).

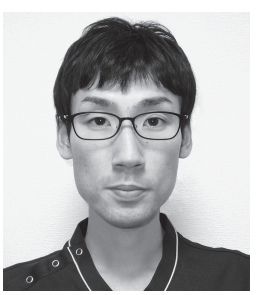

眞田祐太朗（さなだゅうたろう） 2009 年四條畷学園大学リハビリテーショ ン学部理学療法学専攻卒業. 同年, 行岡 病院リハビリテーション科入職. 2017 年神戸海星病院リハビリテーションセ ンター入職, 現在に至る. 日本理学療法 士協会認定理学療法士（運動器・ひとを対象とした基礎領 域). 日本運動器理学療法学会, 日本人工関節学会, 保健医 療学学会の会員. 2015 年保健医療学学会優秀演題賞を受賞. 人工膝関節全置換術のリハビリテーションに関する研究を 行っている.

大澤 傑（おおさわすぐる）

1979 年大阪大学医学部卒業. 1985 年大阪大学大学院博士課 程修了. 医学博士. 現在, 行岡病院副院長, 大阪行岡医療 
大学医療学部教授. 日本整形外科学会専門医, 日本リウマ チ学会指導医, 日本リハビリテーション医学会指導医.

椎木孝幸（しいきたかゆき）

1995 年行岡リハビリテーション専門学校卒業. 理学療法士.

現在, 行岡病院リハビリテーション科統括科長.
今高康詞（いまたかこうじ）

2004 年四條畷学園短期大学卒業. 理学療法士. 現在, 行岡 病院リハビリテーション科主任.

\title{
Difference in the Improvement Rate of Knee Flexion Range of Motion after Total Knee Arthroplasty of the Patients with Knee Osteoarthritis and Rheumatoid Arthritis
}

\author{
Yutaro SANADA ${ }^{1,3 \dagger}$, Suguru OHSAWA ${ }^{1,2}$, Takayuki SHIIKI ${ }^{1}$, Kouji IMATAKA ${ }^{1}$ \\ ${ }^{1}$ Department of Rehabilitation, Yukioka Hospital, \\ ${ }^{2}$ Department of Physical Therapy, Faculty of Health Science, Osaka Yukioka College of Health Science, \\ ${ }^{3}$ [Present] Rehabilitation Center, Kobe Kaisei Hospital
}

\begin{abstract}
To investigate difference in the improvement rate of flexion Range of Motion (ROM) one year after total knee arthroplasty (TKA) of the patients with knee osteoarthritis (knee OA) and rheumatoid arthritis (RA) under conditions where no differences in preoperative ROM. Twenty-eight knees of twenty-two patients with knee OA and seventeen knees of fifteen patients with RA were included in this longitudinal study. Based on the preoperative ROM, we classified subjects into the good ROM group (ROM; 130 degree or more) and the medium ROM group ( $\mathrm{ROM}<130$ degree), and then classified into 2 groups by diagnosis. The improvement degree of knee flexion ROM one year after surgery was calculated and compared between both diseases. In the good ROM group there was no differences in postoperative improvement degree of knee flexion ROM between the knee OA and the RA, however in the medium ROM group the patients with RA were significantly larger than the patients with knee OA. These findings suggest the improvement degree of knee flexion ROM one year after TKA was similar in the both diseases when the preoperative ROM was 130 degree or more, but, that of the patients with RA was larger when the preoperative ROM was less than 130 degree.
\end{abstract}

Key Words : Total knee arthroplasty, Range of motion, Prognosis prediction, Knee osteoarthritis, Rheumatoid arthritis

\footnotetext{
Received Feb. 23, 2017 Accepted Mar. 9, 2018

${ }^{\dagger}$ Yutaro SANADA

Rehabilitation Center, Kobe Kaisei Hospital,3-11-15,

Shinohara Kita-machi, Nada-ku, Kobe-shi, Hyogo, 657-0068, JAPAN,

Tel: 078-871-5201 Fax: 078-871-5206

E-mail: sanada.yutaro@gmail.com
} 